\title{
DIURNAL USE OF RESERVOIRS BY THE INDIAN SARUS CRANE (GRUS ANTIGONE) DURING SUMMER MONTHS
}

\author{
Aeshita Mukherjee ${ }^{1}$, V.C. Soni ${ }^{2}$ and B.M. Parasharya ${ }^{3}$

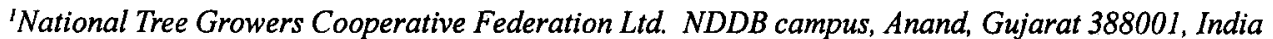 \\ ${ }^{2}$ Department of Biosciences, Saurashtra University, Rajkot, Gujarat 360005, India \\ ${ }^{3}$ AINP on Agricultural Ornithology, Gujarat Agricultural University, Anand Campus, Anand, Gujarat 388110, India
}

\section{Introduction}

Several wetland birds utilise marshes, shallow wetlands and paddy fields during monsoon season. However, during the summer season, when all temporary water bodies dry off, the only remaining water source are the canal linked reservoirs. Due to such drastic change in the area eventually, the existing avian species converge to these wetlands. Along with other birds, Sarus Crane (Grus antigone) is a true wetland species, found extensively utilising these man-made reservoirs to a greater extent during summer season. Understanding the importance of reservoir during summer months, we studied the diurnal use of reservoir at different day light hours. Utilisation of the reservoir by the cranes was governed by variation in the temperature gradient, its bimodal pattern of foraging and the presence of crop pattern in the surrounding area (Mukherjee et al.,1998).

Therefore, the present study was aimed to investigate the importance of canal linked reservoir in sustenance of the Sarus Crane and factors affecting the utilisation of reservoir like presence of crop pattern, temperature, water availability etc. Efforts were made to have roost count at all the reservoirs. Finally the population composition was determined at three basic time intervals (morning, noon, and evening).

\section{Materials and Methods}

This study was carried out during summer months (April to June 1998) to determine the diurnal use of reservoir by the Sarus Crane, and detailed observations were recorded in three reservoirs existing in Matar Tahsil of Kheda District, Gujarat.

Narda Reservoir: Narda reservoir is a small irrigation tank with maximum water holding capacity of $0.574 \mathrm{MCM}$, situated near Limbasi Village $\left(23^{\circ} 35^{\prime} \mathrm{N}, 7^{\circ} 38^{\prime} \mathrm{E}\right)$. The shallow reservoir of 57 ha is very rich in aquatic vegetation, particularly Nelumbo nucifera Gaertn. (Nelumbonaceae) and Typha augustata (Typhaceae). During the study period, water level was at dead storage showing a dry open reservoir bed at several places. No crop was grown around the reservoir. Observations were made on April 16, May 20, and June 5, 1998. The bird count was

Received 28 December 1998;

Accepted 28 May 1999 monitored from $0530 \mathrm{hr}$ to $1900 \mathrm{hr}$. During each hour, arrival and departure of the cranes was noted and by the end of each hour, total number of cranes present within the reservoir was counted. At the end of the daylight period, total number of cranes present in the reservoir was counted along with their population composition (number of males, females and subadults).

Gobrapur Reservoir: Gobrapur, a reservoir $5 \mathrm{~km}$ south to Narda is spread over 56 ha area with maximum water holding capacity of $1.569 \mathrm{MCM}$. Observations were taken for a single day on May 8, 1998 following the same method. There were no crops around the reservoir during the whole summer and the reservoir was at dead storage level with plenty of marshy vegetation surrounded by dense growth of Typha augustata.

Traj Reservoir: Traj reservoir situated $10 \mathrm{~km}$ north west of Narda Reservoir is spread over 44 ha with $0.261 \mathrm{MCM}$ water holding capacity. On May 5 and 21, 1998 crane count was made. Water level of the reservoir was at its maximum level and the surrounding area was green with paddy crop.

Diurnal use of the reservoir by the cranes was studied following the same method and parameters.

\section{Result}

The diurnal pattern of wetland utilisation by the Sarus Crane is summerised below.

Narda: Diurnal crane count on Narda Reservoir during the summer month is shown in figure 1. On April 16, crane number on the reservoir before sunrise was 93 , which was exactly the same that roosted in the earlier night. Seventy cranes departed for foraging outside the reservoir within 20 minutes after sunrise at $0620 \mathrm{hr}$. Three to fifteen cranes always remained on the reservoir between $0800 \mathrm{hr}$ and $1200 \mathrm{hr}$. The cranes started arriving to the reservoir by $1218 \mathrm{hr}$ and maximum number of 32 cranes was counted at $1233 \mathrm{hr}$, which remained in the reservoir till $1633 \mathrm{hr}$. By $1635 \mathrm{hr}$., all the cranes left the reservoir. Once again by $1745 \mathrm{hr}$, the crane started arriving at the reservoir. A maximum count of 93 birds was made by the end of $1900 \mathrm{hr}$ (Sunset $1859 \mathrm{hr}$.). There were 91 adult birds and 2 subadults in the reservoir for night roost. 
On 20 May, 90 cranes were recorded before sunrise $(0558 \mathrm{hr})$. Immediately after sunrise, 50 cranes left the reservoir, and 40 cranes remained in the reservoir throughout the day. Maximum count of 63 birds was made at $1300 \mathrm{hr}-1500 \mathrm{hr}$. Few cranes (22) left the reservoir by $1548 \mathrm{hr}$. Once again the incoming of the cranes started by $1705 \mathrm{hr}$ to the reservoir for the night roost (Sunset $1914 \mathrm{hr}$ ). At the end of the day 90 birds ( 88 adults and 2 subadults) were recorded.

On June 5, 82 cranes were found in the reservoir before sunrise $(0555 \mathrm{hr})$ which decreased to 35 at $0600 \mathrm{hr}$. These birds remained at the reservoir until $1015 \mathrm{hr}$., leaving two adults and a subadult in the reservoir. This pair with subadult remained in the reservoir throughout the day. The cranes started arriving to the reservoir again for noon roosting at $1230 \mathrm{hr}$., in addition at $1417 \mathrm{hr}$., five more cranes arrived at the reservoir. The cranes started departing from the reservoir by $1545 \mathrm{hr}$. By $1812 \mathrm{hr}$ once again, 69 cranes were recorded at the reservoir and by $1830 \mathrm{hr}, 80$ adults and 2 subadults were recorded (Sunset 1921hr.).

During summer, cranes used the reservoirs both for noon and night roosting. However, the number of cranes roosting during noon was always lower than that of night. Both during April and June, most of the cranes left the reservoir for foraging in the agricultural area during morning and evening period. However, during May, this trend was not seen. At least 40 cranes remained at the reservoir throughout the day probably due to extreme food depletion in the agricultural area and high temperature. But during the first week of June when the water was released into the sub minor canal, where the cranes found the additional sites for combating the heat stress. Consequently, like April the crane started showing bimodal dispersal from the reservoir.

Gobrapura: Though only one observation was made, the trend observed was entirely different. All through the day, 109 cranes remained in the reservoir. Only a few cranes departed from the reservoir during morning and evening hours for foraging. This trend was similar to the trend found at Narda on May 20, 1998.

Traj: On May 5, no crane was seen throughout the day at the reservoir. Only three cranes (two adults and one subadult) were seen at the marsh adjoining the reservoir, but they never turned up in the reservoir. At $1800 \mathrm{hr}$ only seven adults landed at the edge of the reservoir, but immediately left the place. Same pattern of reservoir use was noticed on May 21. However seven adults remained at the reservoir between 1225 to $1617 \mathrm{hr}$. At $1800 \mathrm{hr}$., only three cranes were recorded at the reservoir. However at the time of sunset (1907hr.) no crane was found roosting in the reservoir. On the same day, we recorded 92 cranes roosting at Machiyel tank which is $3 \mathrm{~km}$ away from the Traj Reservoir. On May 24, 44 cranes were seen in the paddy fields and 27 cranes were located at Machiyel tank between 1330 and $1415 \mathrm{hr}$. Hence Traj Reservoir was not utilised for night roosting as the water level was too high. In addition, shallow water tank like Machiyel was available near by which substituted the need for noon and night roosting.
At Daloli Reservoir though continuous crane count was not done, occasional crane count was taken at different time of the day which revealed that both during morning and evening almost all the cranes left the reservoir for foraging in the agricultural fields. During noon hours, 105 cranes were recorded on 18 May, which was lower than the night roost count (152); a similar trend as observed at Narda Reservoir.

Population composition at three different periods of the day: In all the three periods of observation during the summer population of male was always higher than the female (Table 1). Single pair with one juvenile was observed throughout the day light period utilising the reservoir. As the temperature hiked, the population showed a trend of increase, both in the number of female as well as males. During June 1998, sex ratio of male to female during morning was (1:0.56), at noon (1:0.66) and in the evening (1:0.51).

General activity on the reservoir: The reservoirs were mainly used for either noon roost or night roost or as both depending upon the physical condition of the reservoir and the presence of crop pattern around. The shallow water depth preferably $<30 \mathrm{~m}$ and formation of small islands within the reservoir were the features preferred for roosting purpose. During April and June when the ambient temperature was relatively less compared to May and there was sufficient food in the form of shattered grains available in the fallow crop fields, the cranes showed bimodal dispersal from the reservoir for foraging. The time of the noon hours spent on the reservoir was mainly to avoid the heat stress. The cranes spent most of their time standing in the water, loafing, preening, bathing, drinking etc. Only few cranes showed occasional foraging activity.

In May, at Narda and Gobrapura when the surrounding area of the reservoir was devoid of crop or any other water source, the cranes remained in the reservoir throughout the day. Even within the reservoir, they showed a specific bimodal feeding pattern. In the early morning they foraged little away from the water, but as the sun came high, they stopped foraging and started moving more towards the water. Even within the reservoir they preferred to occupy the thick vegetation area or in shade under trees on the reservoir boundaries. While on the reservoir, they performed several daily activities like preening, standing, loafing, and other social behaviour. In the evening, they spent relatively more time in foraging.

\section{Discussion}

Like all the true wetland birds, the Sarus Crane also depends on the wetland for its sustenance in terms of food and shelter. During summer months as the wetlands shrink and the only option remaining to fulfil the need of the crane are the canal linked reservoirs around the area. At the same time during this period the ambient temperature rises up to $45^{\circ} \mathrm{C}$, compelling the cranes to converge into the reservoir to overcome the heat stress. Similar behavior was also noted at Keoladeo National Park (KNP) (Ramachandran \& Vijayan, 1994). At night, the reservoirs are 
Table 1. Population composition of Sarus Crane during different period of the day.

\begin{tabular}{|c|c|c|c|c|}
\hline Month & Morning & Noon & & Evening \\
\hline & M F F & $M F$ & $\mathbf{J}$ & $M F$ \\
\hline
\end{tabular}

$\begin{array}{llllllllll}\text { April } & 7 & 3 & 1 & 18 & 12 & 2 & 6 & 25 & 2 \\ \text { May } & 26 & 10 & 2 & 45 & 16 & 2 & 69 & 19 & 2 \\ \text { June } & 16 & 9 & 2 & 39 & 26 & 1 & 53 & 27 & 2\end{array}$

Sex-ratio 1.0 .56

1:0.66

$1: 0.51$

the only safer sites for roosting. Unlike the wintering cranes (Soni et al.,1993) Sarus Cranes also shows the noon and night roosting at the wetlands because of its inherent tendency.

Unlike other bird species Sarus Crane showed a bimodal feeding pattern, which is evident from the observation at different period of the day. During this study, at least twice we have seen that cranes did not leave the reservoir, but remained within it. The reason can be attributed to maximum heat stress of the season and similarity in the physical condition of the reservoir and the crop pattern around the reservoir.

The'study also showed that during noon hours between 1230 and $1600 \mathrm{hr}$ neither arrival nor departure of the cranes from or to the reservoir was noticed. Wintering Demoiselle and Common Cranes show similar pattern of wetland utilisation in Gujarat (Soni et al., 1993; Mukherjee \& Parasharya, 1998; Khachar et al.,1991; Gole, 1984; Banerjee \& Gopakumar, 1986). Moreover, a general trend that less number of cranes were found in the reservoir during the noon hours compared to the night. This suggests that few cranes must be using other small water bodies around during the noon hours. Our earlier studies clearly showed that number of crane concentrated on the reservoir only during summer months. As revealed from the data of the Traj Reservoir, the presence of crop around the reservoir, provided an additional habitat to combat heat stress.

\section{Conclusion}

Canal linked reservoirs are the only suitable sites for the sustenance of the Sarus Crane during summer months. The bimodal pattern of foraging activity was also evident from the study. Under the heat stress, the crane number remained constant between $1230-1600 \mathrm{hr}$. when the crane count could be done most accurately. The physiognomical characters of the reservoir and the presence of the crop fields around Narda and Gobrapura was same, but absolutely different at Traj. As a result of which cranes do not show diurnal pattern of reservoir utilisation even during the hot summer at Traj Reservoir.
Night roost count showed a better population size compared to the count at day time, with a minimal variation. Study reveals that shallow water bodies like Machiyel was preferred over the large water bodies with greater level of water for the night roost. As the number of cranes counted at night were absolutely same as in the coming morning, suggests that the cranes do stay throughout the night at the same area. Therefore high temperature (heat stress), shallow water depth and crop pattern around the reservoir are the determining factors influencing the diurnal use of reservoir by the Indian Sarus Crane.

\section{Acknowledgement}

One of the author Aeshita Mukherjee is thankful to National Tree Growers Cooperative Ltd. for providing computer facilities and other technical assistance.

\section{References}

Banerjee, A. and G. Gopakumar (1986). Effects of drought on the wintering cranes at Rajkot, Saurashtra. Cheetal 27(3):31-33.

Gole, P. (1984). Cranes wintering in Saurashtra. J. Bombay nat. Hist. Soc. 81:699-700.

Khachar, S., H.R. Patankar., A. Gaekwad., T. Mundkur., R. Parvez. and R.M. Naik (1991). Wintering cranes in Gujarat State, India. In: Proceedings of the 1987. International Crane Workshop (ed.J.Harris). International Crane Foundation, Baraboo, USA, pp. 327-333.

Mukherjee, A., C.K. Borad and B.M. Parasharya (in press). An estimation of population size of Indian Sarus Crane and factors affecting its distribution in Kheda district, Gujarat.

Mukherjee, A. and B.M. Parasharya (in press). Concentration of wintering cranes in Saurashtra.

Ramachandran, N.K. and V.S. Vijayan (1994). Distribution and general ecology of the Sarus Crane (Grus antigone) in Keoladeo national park, Bharatpur, Rajasthan. J. Bombay nat. Hist. Soc. 91: 211-223

Soni,V.C., V. Vijaykumar and R. Lathigara (1993). Studies on the crop depredation of Common and Demoiselle Cranes and Indian black ibis in groundnut ecosystem in Saurashtra. A final Progress report submitted to the ICAR, New Delhi; Saurashtra University, Rajkot.

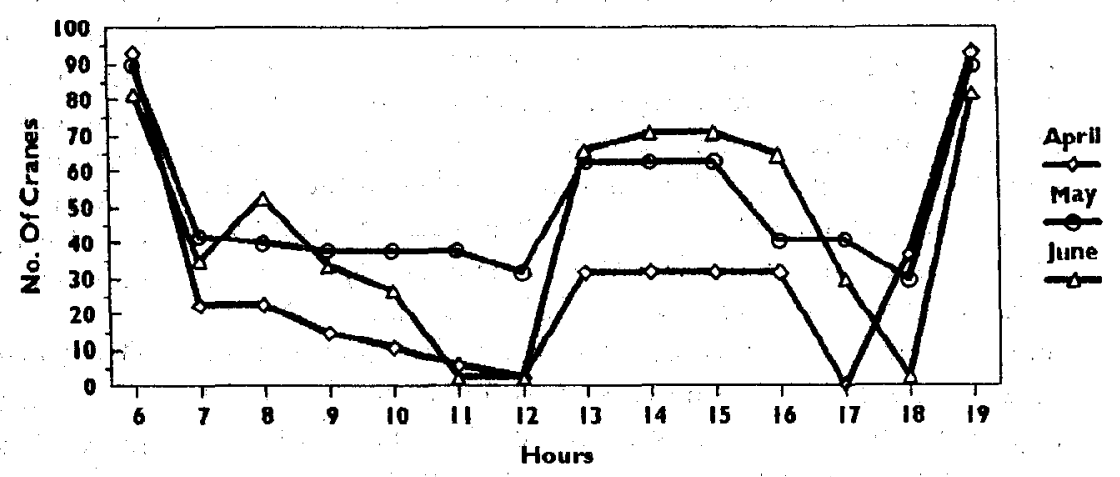

Figure 1. Diurnal use of reservoir by Indian Sarus Crane. 